\title{
A human astrocytoma cell line is highly susceptible to infection with Trypanosoma cruzi
}

\author{
Juan Camilo Vargas-Zambrano', Paola Lasso², Adriana Cuellar³, \\ Concepción Judith Puerta² ${ }^{2}$ John Mario González ${ }^{1 /+}$
}

\author{
${ }^{1}$ Grupo de Ciencias Básicas Médicas, Facultad de Medicina, Universidad de los Andes, Bogotá, Colombia \\ ${ }^{2}$ Laboratorio de Parasitología Molecular ${ }^{3}$ Grupo de Inmunobiología, Facultad de Ciencias, Pontificia Universidad Javeriana, Bogotá, Colombia
}

\begin{abstract}
Astrocytes play a vital role in neuronal protection, homeostasis, vascular interchange and the local immune response. Some viruses and parasites can cross the blood-brain barrier and infect glia. Trypanosoma cruzi, the aetiological agent of Chagas disease, can seriously compromise the central nervous system, mainly in immunesuppressed individuals, but also during the acute phase of the infection. In this report, the infective capacity of $\mathrm{T}$. cruzi in a human astrocyte tumour-derived cell line was studied. Astrocytes exposed to trypomastigotes (1:10 ratio) produced intracellular amastigotes and new trypomastigotes emerged by day 4 post-infection (p.i.). At day 6 p.i., 93\% of the cells were infected. Using flow cytometry, changes were observed in both the expression of major histocompatibility complex class I and II molecules and the chemokine secretion pattern of astrocytes exposed to the parasite. Blocking the low-density lipoprotein receptor on astrocytes did not reduce parasite intracellular infection. Thus, T. cruzi can infect astrocytes and modulate the immune response during central nervous system infection.
\end{abstract}

Key words: astrocytes - Trypanosoma cruzi - neuroimmunology

Chagas disease, which is caused by Trypanosoma cruzi, is endemic in Latin America, where it is estimated that seven million people are infected (OPS 2007). Acute Chagas disease is usually asymptomatic and widely under-diagnosed, mainly because the symptoms are constitutive when the disease is clinically apparent (Pittella 2009, Cordova et al. 2010). Parasites can be found in peripheral blood samples of acutely infected individuals, which allows for direct diagnosis using blood smears (Coura \& Borges-Pereira 2010). During acute onset, a relatively efficient host immune response correlates with parasitaemia reduction, but not its complete clearance. As a consequence, $T$. cruzi persists and induces the chronic phase of the disease (Dutra \& Gollob 2008). Chronic patients can remain asymptomatic for decades (known as the indeterminate phase) and their diagnosis is usually made by $T$. cruzi antibody-specific tests. Unfortunately, nearly $30 \%$ of indeterminate individuals develop cardiac and gastrointestinal damage (Dutra \& Gollob 2008, Pittella 2009, Coura \& Borges-Pereira 2010). The development of meningoencephalitis in Chagas disease is considered rare, but it is sometimes observed during acute infection, mainly in children younger than two years of age (Cordova et al. 2010). The involvement of the central nervous system (CNS) is a life-threatening condition

Financial support: Vicerrectoría de Investigaciones, Universidad de los Andes

PL was supported by the PhD National Program, COLCIENCIAS 2011. + Corresponding author: johgonza@uniandes.edu.co

Received 10 September 2012

Accepted 18 December 2012 that can also occur as a reactivation of the disease during the chronic stage in immunosuppressed hosts. Although Carlos Chagas described the CNS compromise 100 years ago, it was not until 1969 that Mattosinho-Franca et al. (1969) reported the first case of T. cruzi CNS infection, which was found to involve parasite reactivation in a patient with chronic lymphocytic leukaemia. Currently, reactivation of Chagas disease occurs after immunesuppression therapy, most importantly in the context of human immunodeficiency virus/acquired immune deficiency syndrome (HIV/AIDS) (Pittella 2009). In HIVinfected individuals, disease reactivation is severe and often lethal. The clinical manifestations include fever, headache, focal neurological deficits, seizures and altered mental status. Histologically, the damage consists of necro-haemorrhagic nodules in the white matter with T. cruzi amastigotes localised within the glia (Cordova et al. 2008, 2010, Pittella 2009). Cellular infiltration of the brain parenchyma and the perivascular space with lymphocytes, macrophages, some plasma cells and neutrophils is also observed (Chimelli \& Scaravilli 1997, Cordova et al. 2008, Pittella 2009). Several studies have aimed to describe the association between the parasite's genetic diversity and the clinical status and organ tropism (Andrade \& Magalhães 1996, Andrade et al. 2010). The T. cruzi population is divided into six discrete typing units, TcI to TcVI (Zingales et al. 2009). Although there is no conclusive evidence, TcI seems to cause CNS disease in AIDS patients (Burgos et al. 2008).

Mouse models of $T$. cruzi CNS involvement have shown that $\mathrm{CD} 8^{+} \mathrm{T}$ cells expressing integrin VLA-4 infiltrate the brain parenchyma (Roffe et al. 2003), while rat models have increased CNS-derived tumour necrosis factor- $\alpha$, interleukin (IL)-10, interferon (IFN)- $\gamma$, CCL2/ MCP-1, CCL3/MIP-1 $\alpha$ and CCL5/RANTES levels (Ra- 
chid et al. 2010). In both of the above-mentioned rodent models, glia but not neurons harbour amastigotes (Pitella 2009). As glia represent an important source of CNS cytokines and chemokines, these cells should participate actively in the physiopathology of T. cruzi infection. Astrocytes are the most abundant cells in brain tissue (Seth \& Koul 2008) and they are important in the maintenance of an adequate environment for neurons, as they regulate CNS blood flow and provide metabolic substrates (Seth \& Koul 2008, Sofroniew \& Vinters 2010). They also have immune functions, such as endocytosis and antigen presentation (Seth \& Koul 2008, Wang \& Bordey 2008). Astrocytes can host several infectious agents, including viruses and parasites, such as Toxoplasma gondii (Halonen et al. 1996, Wilson \& Hunter 2004). T. gondii CNS infection induces astrocyte secretion of CXCL10/IP-10, CCL2, IL-1, IL-6 and IL-10 (Daubener et al. 1996). Each of these chemokines promotes CNS cellular infiltration (Wilson \& Hunter 2004). Consequently, the aim of this work was to assess whether a human astrocytoma cell line could serve as host for T. cruzi and to determine the changes in cell viability, human leukocyte antigen (HLA) expression and chemokine production that could be involved in the immune response against $T$. cruzi.

\section{MATERIALS AND METHODS}

Cell culture - CRL-1718 (ATCC, Manassas, VA, USA) cells, which were derived from a grade IV human astrocytoma, were grown in T25 culture flasks and maintained in RPMI-1640 medium (Sigma-Aldrich, St. Louis, MO, USA) supplemented with $10 \%$ foetal bovine serum (FBS) (Eurobio, Les Ulis, France), 2 mM L-glutamine (Gibco, Auckland, New Zealand), $1.5 \mathrm{~g} / \mathrm{L}$ sodium bicarbonate, $4.5 \mathrm{~g} / \mathrm{L}$ glucose, $10 \mathrm{mM}$ HEPES and $1 \mathrm{mM}$ pyruvate (all from Gibco) at $37^{\circ} \mathrm{C}, 5 \% \mathrm{CO}_{2}$. Cell transfers were performed by replacing medium with $0.25 \%$ trypsin-EDTA (Gibco) for $3 \mathrm{~min}$ at $37^{\circ} \mathrm{C}$. Cell detachment was verified by inverse light microscopy and 5\% FBS-supplemented RPMI-1640 medium was added to block the trypsin reaction. The cells were transferred to a $15 \mathrm{~mL}$ tube, centrifuged for $5 \mathrm{~min}$ at $1,350 \mathrm{~g}$ and used either for sub-culturing or for experiments.

Parasite culture - Trypomastigotes of the T. cruzi I DA strain (MHOM/CO/01/DA) were obtained from an acutely infected human donor in the town of Sutatenza, Boyacá, Colombia (Barrera et al. 2008). Parasites were maintained in Vero cells and kept frozen in DMEM (Sigma-Aldrich) containing 10\% FBS (Eurobio) and 10\% DMSO (MP Biomedicals, Solon, OH, USA).

Astrocytoma cell line infection - Culture flasks (T25) containing $1 \times 10^{6}$ astrocyte cells were infected with 1 x $10^{7}$ recently thawed trypomastigotes. Infected astrocyte cultures were kept for three weeks before obtaining trypomastigotes for astrocyte infection assays. Parasite number and viability were verified by light microscopy using a Neubauer chamber and trypan blue staining. Astrocytes $\left(5 \times 10^{5}\right)$ were cultured in small Petri dishes (35 mm x $10 \mathrm{~mm}, 9.2 \mathrm{~cm}^{2}$ ) for $48 \mathrm{~h}$. Later, confluent cell cultures were infected with $5 \times 10^{6}$ trypomastigotes (1:10 ratio). The infection was then evaluated two-six days post-infection (p.i.). Cells for each experimental condition were methanol-fixed and stained with $4 \% \mathrm{Gi}$ emsa (Albor, Bogotá, Colombia). Stained cultures were observed under light microscope and the percentage of infected cells and quantity of amastigotes per cell were determined under 100X magnification. At least 100 cells were used to determine the percentage of infection and the quantity of amastigotes.

Major histocompatibility complex (MHC) molecule expression and cell mortality - Uninfected astrocytoma cells $\left(5 \times 10^{4}\right)$ were sub-cultured and infected with $T$. cruzi in 48-well microplates. The expression levels of HLA class I and HLA class II molecules and mortality were determined at days 2,4 and 6 p.i. using flow-cytometric analysis of cells from infected and uninfected (control) wells. Astrocytoma cells were detached from each well as previously described and then incubated with $2 \mu \mathrm{L}(12.5 \mu \mathrm{g} / \mathrm{mL})$ anti-HLA-DR APC (clone L243, BD Pharmingen, San Diego, CA, USA) and $1 \mu \mathrm{L}$ antiHLA-ABC FITC (clone G46-2.6, BD Pharmingen) for $20 \mathrm{~min}$ at room temperature (RT) and $5 \mu \mathrm{L}(1 \mu \mathrm{g} / \mathrm{mL})$ propidium iodide (PI) for an additional $5 \mathrm{~min}$ in darkness (DakoCytomation, Glostrup, Denmark). The cells were acquired using a BD FACSCanto II (BD Biosciences, San Jose, CA, USA) and analysed using FACSDiva v.6.1.3 (BD Biosciences). At least $1 \times 10^{4}$ PI-negative cells (live cells) were acquired in each experimental condition and gated based on cell size and granularity [forward scatter (FSC) vs. side scatter (SSC)] using uninfected cells as a template. A more comprehensive analysis was performed on cells from infected wells; cells with the same size and granularity as the controls were considered uninfected cells. A second gate was created with larger and more granular cells, according to the FSC and SSC patterns, which presumably corresponded to infected cells. Mortality was analysed in PI-positive cells and the expression markers were measured only on PI-negative cells.

Chemokine expression - Supernatants were collected at days 2 and 4 p.i. from infected and uninfected wells. The cells were centrifuged for $10 \mathrm{~min}$ at $5,400 \mathrm{~g}$ and stored at $-80^{\circ} \mathrm{C}$. The CCL2 (MCP-1), CCL5 (RANTES), CXCL8 (IL-8), CXCL9 (MIG) and CXCL10 (IP-10) concentrations in the supernatants were measured using a $\mathrm{BD}$ cytometric bead array human chemokine kit (BD Biosciences, San Diego, CA, USA). Chemokine concentrations were estimated using BD FCAP software v.1.0.1 (BD Biosciences).

Low-density lipoprotein receptor (LDLr) detection - Astrocytes were tested for the presence of LDLr using two different rabbit polyclonal antibodies: the $\mathrm{Ab}$ cam antibody $30532(0.8 \mathrm{mg} / \mathrm{mL})$ directed against the LDLr cell-surface epitope (Abcam, Cambridge, MA, USA) and the Abcam antibody 52818, which recognises an intracellular C-terminal epitope. Astrocytes were incubated with $10 \mu \mathrm{L}$ of a 1:100 dilution of each primary antibodies for $20 \mathrm{~min}$ at RT and the cells for the intracellular epitope were fixed with $4 \%$ formaldehyde and permeated with $0.1 \%$ Tween 20 in $1 \mathrm{x}$ phosphate buffered saline. After washing, an anti-rabbit Alexa Fluor 
488 antibody (Molecular Probes, Eugene, OR, USA) was added at 1:1000 dilution for $20 \mathrm{~min}$ in darkness, followed by an additional 5-min incubation with DAPI $30 \mu \mathrm{g} / \mathrm{mL}$ (Molecular Probes). The slides were read at 60X under a Nikon Eclipse TI fluorescent microscope (Nikon Instruments Inc Melville, NY, USA).

LDLr blockage - LDLr is a putative receptor for T. cru$z i$ infection in human-derived fibroblasts (Nagajyothi et al. 2011). To determine the participation of this receptor in astrocyte infection, cultures containing $5 \times 10^{5}$ cells were incubated with $10 \mu \mathrm{L} / \mathrm{mL}$ of cell-surface epitope-specific LDLr antibody (Abcam 30532) for $1 \mathrm{~h}$ at $37^{\circ} \mathrm{C}$. Next, 5 x $10^{6}$ trypomastigotes were added to each well containing cells incubated with medium alone or with anti-LDLr antibody. In some experiments, an anti-rabbit polyclonal antibody against human ISG-15 (Cell Signaling, Danvers, MA, USA) was used as control. The cultures were allowed to grow and the cells were evaluated blindly for infection in $4 \%$ Giemsa-stained wells as described above.

Statistical analysis - The arithmetic mean, standard deviation and percentages were calculated. The Kolmogorov-Smirnoff test was used to determine the distribution of the data. If they had a normal distribution, parametric tests (Student's $t$ and ANOVA) were used; otherwise, non-parametric tests (Mann-Whitney $U$ and Kruskal-Wallis) were employed. $\mathrm{p}<0.05$ was considered statistically significant. SPSS v.18 was used to perform the calculations (IBM, Somers, NY, USA).

\section{RESULTS}

T. cruzi infects a human astrocytoma cell line - The percentage of infected cells and number of amastigotes per cell were determined at days 2-6 p.i. Amastigotes were observed within cells $48 \mathrm{~h}$ after exposure to $T$. cru$z i$ trypomastigotes. As shown in Fig. 1A, the percentage of infected cells increased with time. Indeed, at day 6 p.i., the majority of cells contained intracellular amastigotes. Likewise, the number of amastigotes per cell also increased with time (Fig. 1B). More than 300 amastigotes were observed in a single astrocyte (Fig. 2A, B), inducing an increase in astrocyte cytoplasm and nucleus size. Around day 4 p.i., amastigotes transformed into trypomastigotes and were then released into the culture medium (Fig. 2B), causing a significant increase in the percentage of infected cells on day 5 p.i. (Fig. 1A). Based on this observation, the flow cytometry gating was performed according to cell size (FSC detection) and cytoplasmic complexity (SSC detection) on cells derived from uninfected (Fig. 3B) and infected wells (Fig. 3C).

T. cruzi infection does not alter astrocyte proliferation but increases mortality - The cells from uninfected and infected wells displayed similar numbers of astrocytes at each day p.i. (Fig. 3A). The mortality was slightly higher in infected cells compared with the cells from uninfected wells (Fig. 3B, D) and was especially high in larger cells (Fig. 3C), which presumably corresponded to infected astrocytes, based on the flow cytometry parameters used. Mortality in these infected cells was 3.5 times higher compared with the gate of uninfected cells (Fig. 3D).
HLA class I and II expression increases on T. cruziinfected astrocytes - HLA class II surface expression was induced by T. cruzi infection (Fig. 4A). At days 2, 4 and 6 p.i., the percentage of cells expressing HLA class II molecules was higher in infected cells than controls, (Student's $t$ test $\mathrm{p}=0.008$ ). In the infected wells, the gate containing the larger cells showed the highest number of cells expressing HLA class II molecules (Fig. 4A). Meanwhile, in the uninfected cells from wells exposed to the parasite, the expression of HLA class II molecules did not differ from cells from uninfected wells (Student's $t$ test $\mathrm{p}=0.07$ ). Similarly, the cells from infected wells showed a higher mean fluorescence intensity (MFI) of HLA class I molecules than control cells (Student's $t$ test $\mathrm{p}=0.022$ ) (Fig. 4B). Cells from the parasite-infected wells showed a different HLA class I pattern; the larger cells had a higher HLA class I MFI at day 6 p.i. $(8249.85 \pm 3772)$ compared with normal cells $(5426.3 \pm 2276.59)$ (Student's $t$ test $\mathrm{p}=0.043)$. When HLA class I expression was compared between control astrocytes (uninfected wells) and uninfected astrocytes derived from the parasite-exposed wells, the HLA class I MFI was also statistically different at days 2 and 4 (Fig. 4B) (day 2, Student's $t$ test $\mathrm{p}=0.009$; day 4, Student's $t$ test $\mathrm{P}=0.001$ ).
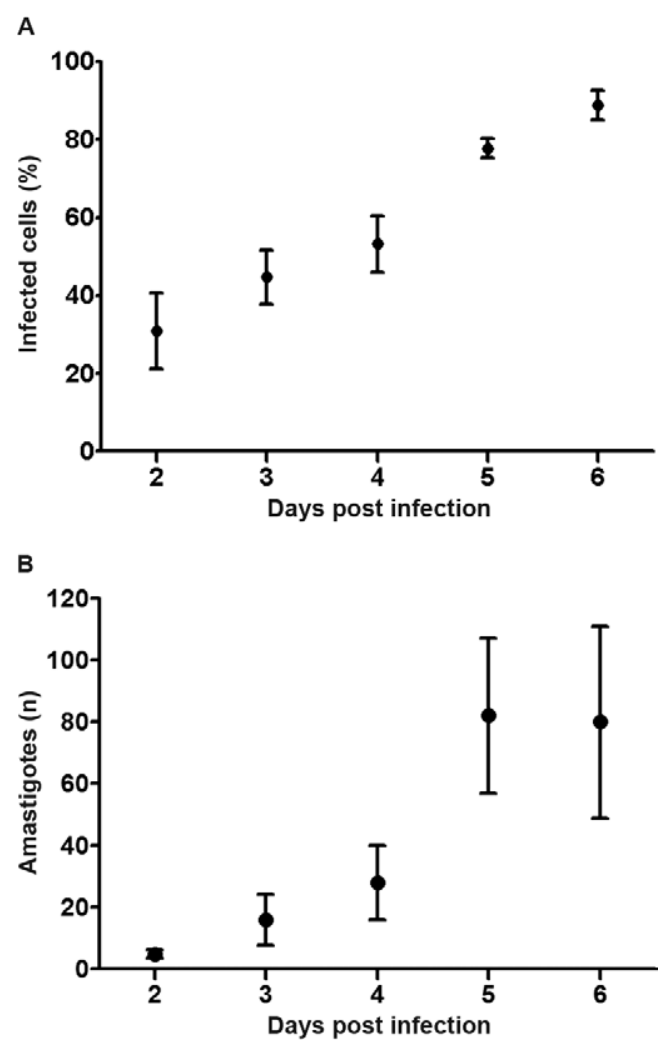

Fig. 1: astrocytes infection with Trypanosoma cruzi. A: mean and standard deviation (SD) of the T. cruzi infected cell percentages according to post-infection day. Percentages of infected cells increased with time; B: mean and SD of the number of amastigotes per cell. Number of amastigotes increased with time as well $(n=5)$. 
T. cruzi infection induces changes in the secretion of various pro-inflammatory chemokines - In all culture supernatants (infected and uninfected wells) chemokines were barely detected at day 2 p.i. At day 4, the levels of CCL5, CXCL9 and CXCL10 in control wells were slightly lower than in infected wells. At day 2 p.i., CCL2 was lower in supernatants of the supernatants from infected wells (1341.91 pg/mL \pm 192.83$)$ than control wells $(1880.12 \mathrm{pg} /$ $\mathrm{mL} \pm 295.2$ ). This trend was also seen at day 4 p.i., in which the CCL2 concentration in the infected wells was $1972.24 \mathrm{pg} / \mathrm{mL} \pm 367.29$ compared with $5560.67 \mathrm{pg} / \mathrm{mL}$ \pm 927.7 in control wells (Student's $t$ test, $\mathrm{p}=2.75 \times 10^{-10}$ ) (Fig. 5A). CXCL8 concentrations at day 2 p.i. were 55.64 $\mathrm{pg} / \mathrm{mL} \pm 7.73$ in the supernatants from the control wells and $319.35 \mathrm{pg} / \mathrm{mL} \pm 55$ in the infected wells $(\mathrm{p}=5.85 \mathrm{x}$ $10^{-13}$ ). At day 4 p.i., CXCL8 increased from $74.05 \mathrm{pg} / \mathrm{mL}$ \pm 7.91 in the control wells to $417.75 \mathrm{pg} / \mathrm{mL} \pm 47.46$ in the infected wells ( $\mathrm{p}=5.25 \times 10-17)$ (Fig. 5B).
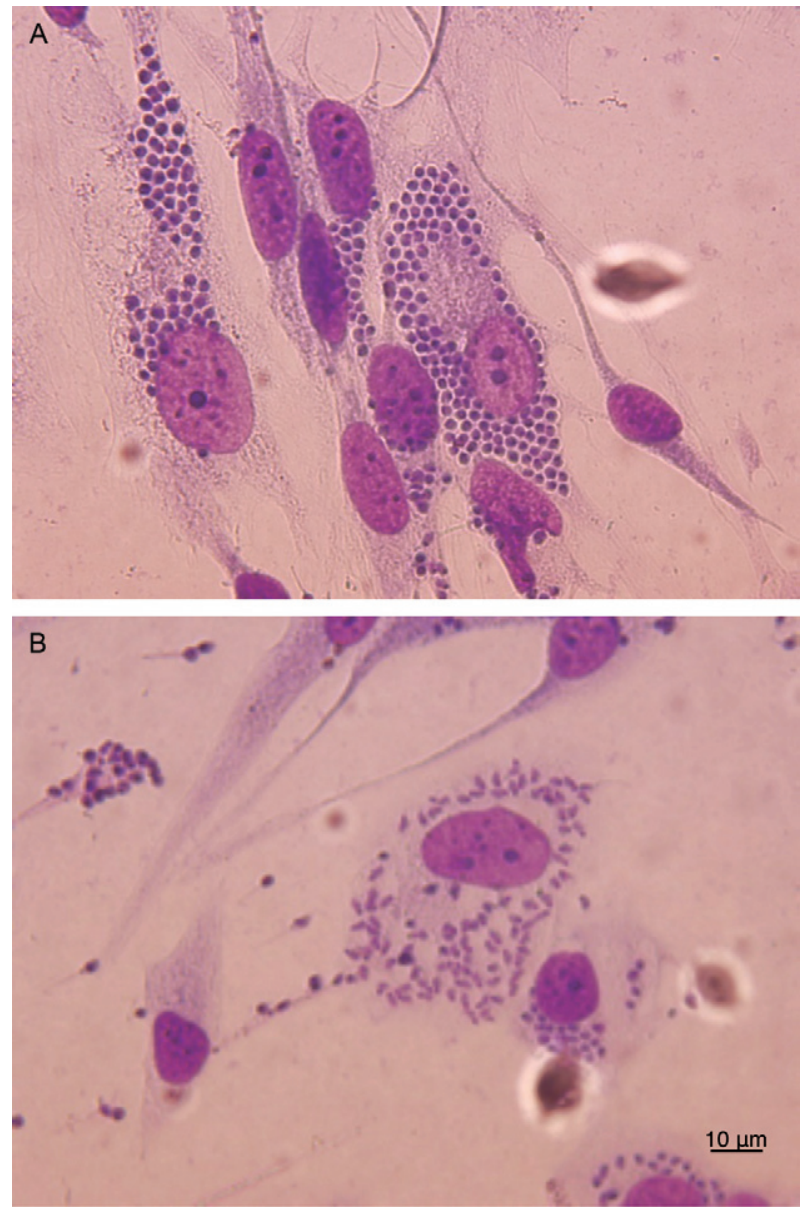

Fig. 2: Giemsa staining of Trypanosoma cruzi in an astrocytoma cell line. Cultured cells during the six days post-infection (p.i.) were methanol fixed and stained with $4 \%$ Giemsa. Selected days are displayed. A: intracellular well-defined amastigotes were found in astrocytes' cytoplasm at day 4 p.i. The cellular membrane is intact. Notice the long-cytoplasm and smaller nucleus of uninfected astrocytes; B: amastigotes differentiated into trypomastigotes and were then released from astrocytes. As consequence in both cases cell morphology of infected cells is affected.
LDLr blockage enhances T. cruzi infection - Using antibodies against the intracellular and extracellular epitopes of LDLr, homogeneous expression of LDLr in the astrocyte cytoplasm and their corresponding prolongations were observed by immunofluorescence. Fig. 6A shows the expression of the surface LDLr on astrocytes. Interestingly, $77.84 \% \pm 10.82 \%$ of cells pre-incubated with the cell-surface LDLr antibody were infected with
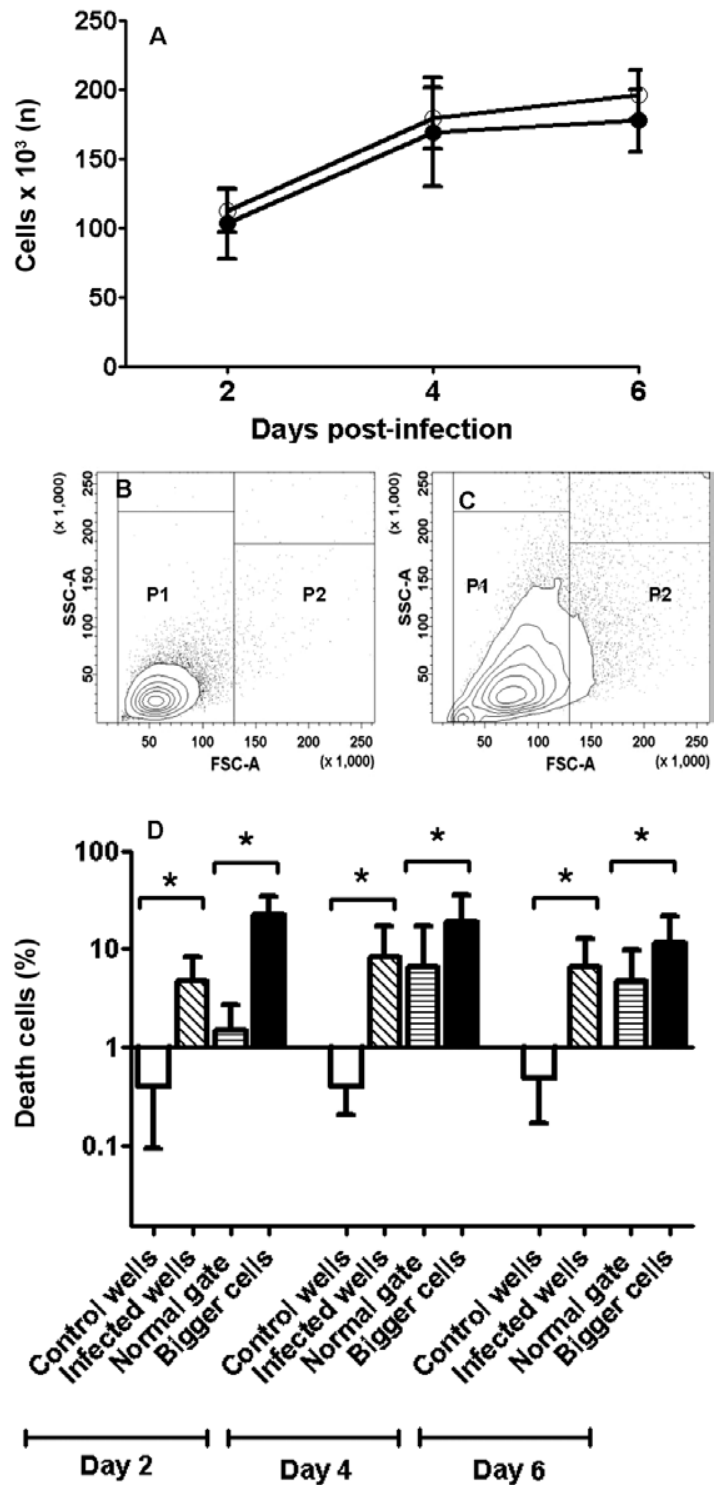

Fig. 3: infection influences astrocytoma proliferation and mortality. A: average cell number and standard deviation (SD) in uninfected wells (empty circle; $\mathrm{n}=12$ ) and infected wells (black circle; $\mathrm{n}=13$ ); B: contour plot of uninfected wells where P1 is considered uninfected astrocytes; C: contour plot of infected cells where P2 is presumably infected astrocytes; D: comparison of mortality (Log scale) in different groups of astrocytes using flow cytometry. Cells from uninfected wells were used as negative controls (empty bars), cells from infected wells (oblique lines), normal cells from infected wells (horizontal lines) and presumably infected cells (black bars) from infected wells. FSC: forward scatter; SSC: side scatter. Asterisk means $\mathrm{p}<0.05 . \mathrm{n}=14$, Student $t$ test. 
T. cruzi at day 3 p.i., compared with $46.09 \% \pm 4.58 \%$ in the control cells $(p=0.0006)$ (Fig. 6B). The number of amastigotes per infected cell was not determined.

\section{DISCUSSION}

Here, we found that the CRL-1718 astrocytoma cell line is susceptible to infection by T. cruzi and hosts the parasite's vertebrate cycle, which leads to trypomastigote infection of nearby cells. In vitro studies of T. cruzi infection and invasion are common and current research tools. However, these studies have included different human cell lines and parasite genotypes. Human monocytes and macrophages are highly permissive to $T$. cruzi infection, with the early presence of intracellular amastigotes (24 h) (Williams \& Remington 1977). HeLa and Hep2 cells are also highly susceptible to infection $(85 \%$ and $60-85 \%$ infected cells when using a 1:40 and 1:10 cell:parasite ratio, respectively) (Sartori et al. 2003, Faria
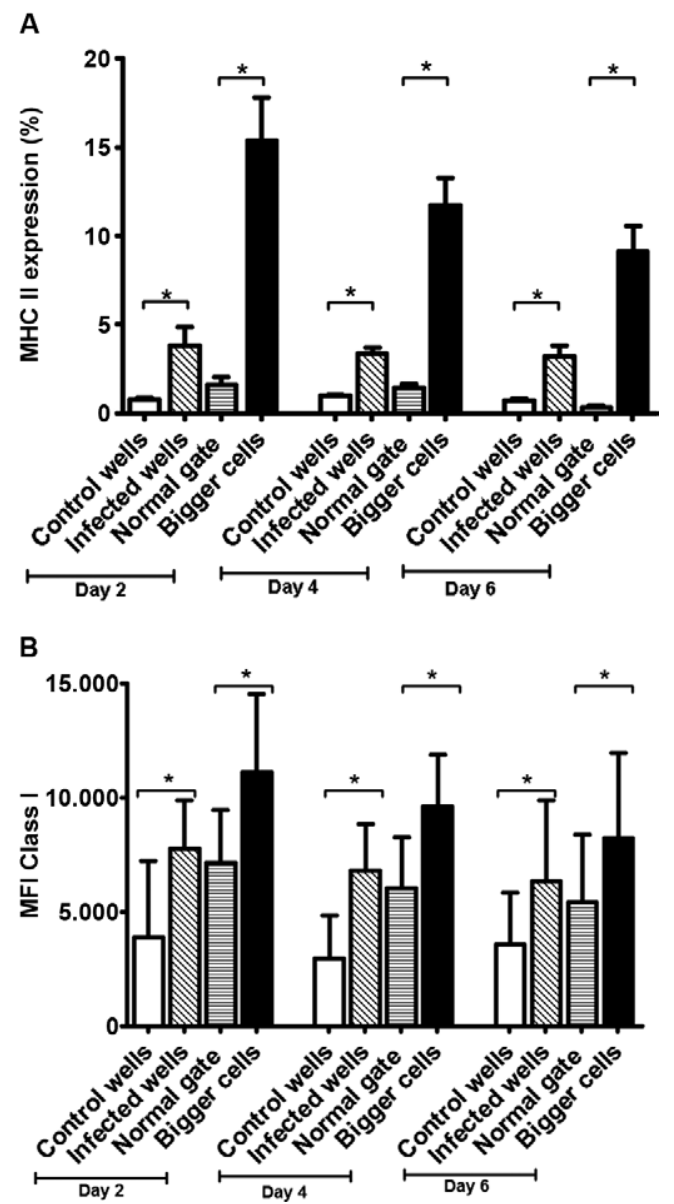

Fig. 4: major histocompatibility complex (MHC) I and II expression on infected astrocytoma cell line. A: mean and standard deviation (SD) of cells expressing MHC II according to the day post-infection (p.i.). Uninfected wells used as negative controls (empty bars), cells from infected wells (oblique lines), normal cells from infected wells (horizontal lines) and presumably infected cells (black bars) from infected wells; B: mean fluorescence intensity (MFI) and SD of MHC I on astrocytes according to the day p.i. Groups were defined as in A. Asterisk means $\mathrm{p}<0.05 . \mathrm{n}=14$, Student $t$ test. et al. 2008). These findings agree with ours despite the fact that the amastigotes used in our system had a better morphology. Vero and BESM (bovine muscle) cells are less susceptible to T. cruzi infection. Vero cells are either $1 \%$ or $8 \%$ infected $18 \mathrm{~h}$ or five days p.i. with a 1:10 cell:parasite ratio using different $T$. cruzi strains (Pires et al. 2008). Similarly, BESM display a $1-4 \%$ infection rate with similar culture conditions (Dvorak \& Howe 1976). It seems that cell lines differ in susceptibility to T. cruzi according to the presence of sialic acid residues on the cell surface (Schenkman et al. 1993); such carbohydrate moieties seem to be crucial to parasite invasion (Epting et al. 2010). Previously, non-glial-derived cells have been used for $T$. cruzi infection. Compared with reports on human cell lines, the astrocytoma cells used here were highly susceptible to $T$. cruzi infection, with $50 \%$ of cells infected at day 3 p.i. and $90 \%$ infection at day 6 p.i. with 1:10 cell:parasite ratio. Despite the fact that mortality was higher in the infected astrocytes due to trypomastigote release, the number of cells in wells
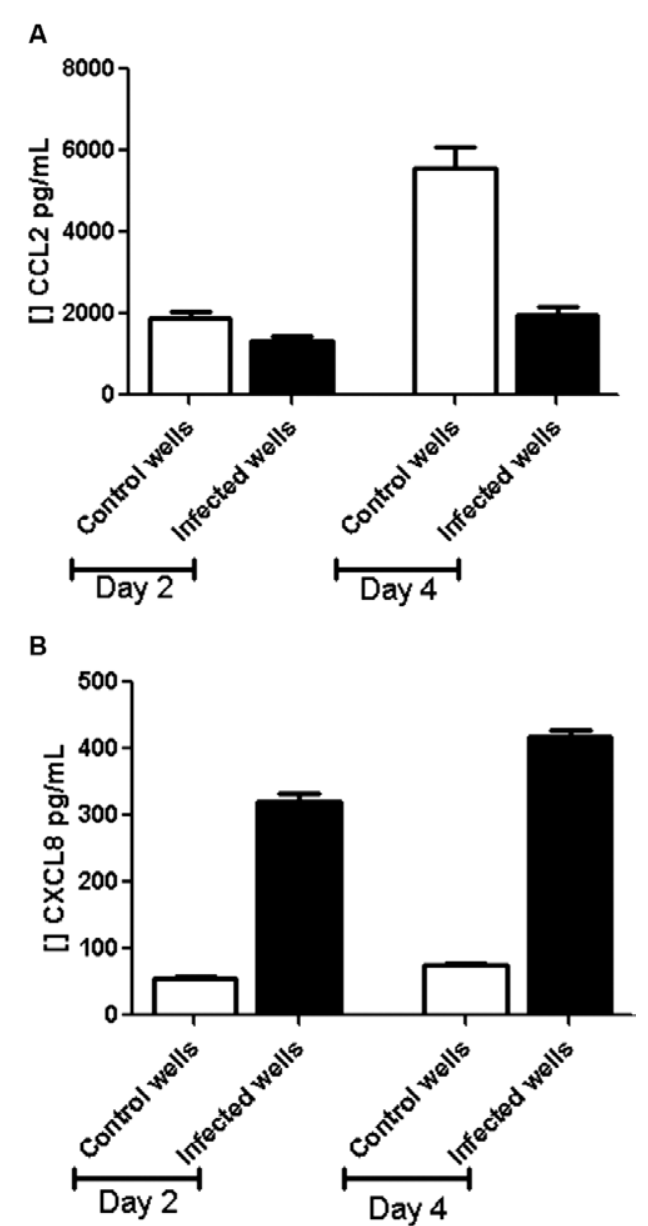

Fig. 5: chemokine secretion on supernatants infected astrocytoma cell line. A: mean and standard deviation (SD) of CCL2 concentration on supernatant at day 2 and 4 post-infection (p.i.) in supernatants on controls (empty bars) and infected wells (black bars); B: mean and SD of CXCL8 concentration on supernatant at day 2 and 4 p.i. on supernatants controls (empty bars) and infected wells (black bars). $\mathrm{n}=15$. 
exposed to the parasite remained quite similar to that of the uninfected cells. It is plausible that parasites induced astrocyte proliferation; this phenomenon has been described in primary human vascular smooth muscle cells, in which $T$. cruzi infection induces cell proliferation (Hassan et al. 2006).

The MFI of MHC class I molecules in infected cells was higher than in uninfected cells. This result correlates with the endogenous antigen-processing pathway, which normally functions to present antigens during intracellular infection (Goldszmid \& Sher 2010), such as $T$. cruzi infection. The percentage of cells expressing MHC II molecules increased mainly on infected cells, which demonstrates that the exogenous pathway of antigen presentation is also active during $T$. cruzi infection, perhaps due to antigen release after the parasite bursts from the cells. Astrocytes can express HLA class II molecules in vivo, as demonstrated in CNS viral infections in mouse models (Hamo et al. 2007), as well as in vitro in human astrocytes (Hirayama et al. 1988). In contrast, other parasites, such as $T$. gondii, downregulate the expression of HLA-DR in infected glioblastoma cell lines (Lüder et al. 2003). Interestingly, IFN $\gamma$-activated astrocytes can act as

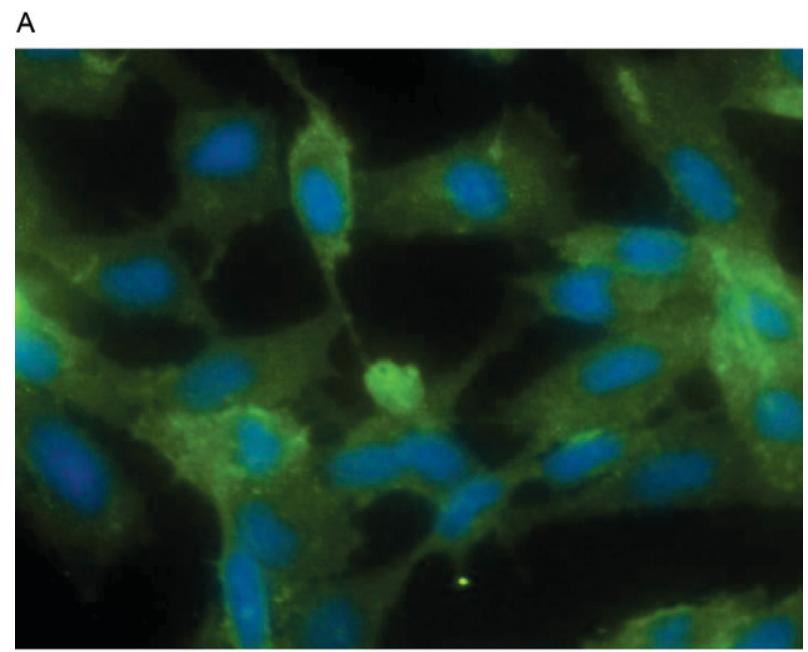

B

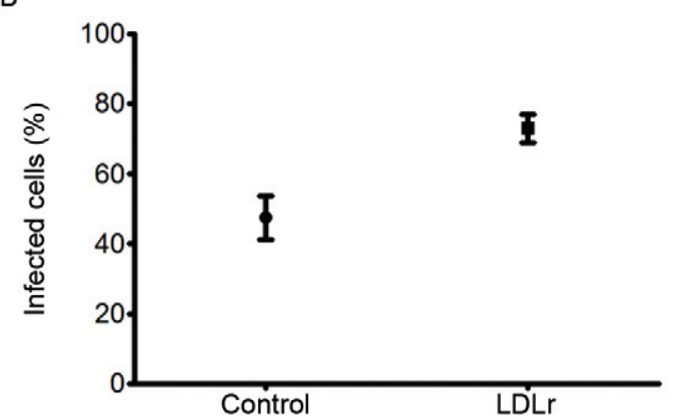

Fig. 6: infection of astrocytes in presence of low-density lipoprotein receptor (LDLr) antibodies. A: immunofluorescence of astrocytoma cell line with LDLr antibodies that recognised an extracellular epitope; B: mean and standard deviation of infection percentage in cells from control or LDLr-antibody inhibited astrocytes. antigen-presenting cells and activate $\mathrm{CD} 4^{+}$helper T cells in multiple sclerosis and experimental autoimmune encephalitis (Hirsch et al. 1983, Fontana et al. 1984, Soos et al. 1998). Our results suggest that parasitic antigens can be presented in both HLA antigen-processing pathways by infected astrocytes during a CNS infection and probably induce a $\mathrm{T}$ cell response. This mechanism could explain the devastating progress of $T$. cruzi CNS infection in AIDS patients who have a low number of CD4 $4^{+} \mathrm{T}$ cells (Pittella 2009, Cordova et al. 2010).

Several glioblastoma cell lines and human primary astrocyte cultures produce all the chemokines tested here (Oh et al. 1999). In this study, T. cruzi infection influenced the production of CXCL8 and CCL2 by astrocytes. Indeed, CXCL8 secretion increased but CCL2 production decreased in supernatants collected from infected cells. CXCL8 and its murine equivalent induce neutrophil activation and chemotaxis (Tani et al. 1996). Indeed, mice infected with T. cruzi in the CNS display tissue infiltration, predominately by mononuclear cells, at day 42 p.i. and by some neutrophils at day 30 (Silva et al. 1999). Interestingly, CNS infection with JHMV coronavirus promotes earlier neutrophil infiltration, which seems to be indispensable for the permeabilisation of the bloodbrain barrier and allows mononuclear cell infiltration for infection control (Zhou et al. 2003). Regarding CNS involvement, little is known about the pathogenesis of T. cruzi infection, but the breakdown of the blood-brain barrier by innate immune cells is an important initial step that precedes the T cell infiltration of the CNS during infection. At day 4 in this study, infected astrocytes displayed CXCL8 upregulation, an important factor for neutrophil chemotaxis. Astrocytes are the main source of CCL2 production in the CNS and increased levels of CCL2 induce endothelial dysfunction in reorganising the tight junction proteins, consequently increasing bloodbrain barrier permeability (Roberts et al. 2012). Here, $T$. cruzi infection of astrocytes decreased CCL2 production, which suggests a possible defence mechanism that astrocytes elicit after intracellular infection in an attempt to inhibit macrophage and lymphocyte entry into the CNS.

Finally, in our model, we could not determine whether the LDLr plays a major role in T. cruzi infection, as demonstrated for other human primary cell lines (Nagajyothi et al. 2011). Astrocyte pre-incubation with an LDLr antibody that recognised the cell-surface epitope did not decrease the percentage of infected cells. T. cruzi can infect cells using other surface molecules, such as the neurotrophic TrkC receptor on glial cells (Weinkauf et al. 2011).

Overall, our work indicates that astrocytes are highly susceptible to T. cruzi infection and can induce the initial steps that trigger a protective immune mechanism, such as antigen presentation and chemokine secretion, as seen in immune-competent individuals with T. cruzi CNS infection.

\section{ACKNOWLEDGEMENTS}

To Elizabeth Suesca and Natalia I Bolaños, Universidad de los Andes, for technical help, and to Gabriel A Duran Rehbein, for reviewing the paper. 


\section{REFERENCES}

Andrade LO, Galvão LMC, Meirelles MNSL, Chiari E, Pena SDJ, Macedo AM 2010. Differential tissue tropism of Trypanosoma cru$z i$ strains: an in vitro study. Mem Inst Oswaldo Cruz 105: 834-837.

Andrade SG, Magalhães JB 1996. Biodemes and zymodemes of Trypanosoma cruzi strains: correlations with clinical data and experimental pathology. Rev Soc Bras Med Trop 30: 27-35.

Barrera YK, Guevara JM, Pavía PX, Montilla M, Nicholls RS, Parra E, Puerta CJ 2008. Evaluation of TcH2AF-R and S35-S36 primers in PCR tests for the detection of Trypanosoma cruzi in mouse cardiac tissue. Biomedica 28: 616-626.

Burgos JM, Begher S, Valdares HM, Bisio M, Duffy T, Levin MJ, Macedo AM, Schijman AG 2008. Case report: molecular identification of Trypanosoma cruzi I tropism for central nervous system in Chagas reactivation due to AIDS. Am J Trop Med Hyg 78: 294-297.

Chimelli L, Scaravilli F 1997. Trypanosomiasis. Brain Pathol 7: 599611.

Cordova E, Boschi A, Ambrosioni J, Cudos C, Corti M 2008. Reactivation of Chagas disease with central nervous system involvement in HIV-infected patients in Argentina, 1992-2007. Int J Infect Dis 12: 587-592.

Cordova E, Maiolo E, Corti M, Orduna T 2010. Neurological manifestations of Chagas disease. Neurol Res 32: 238-244.

Coura JF, Borges-Pereira J 2010. Chagas disease: 100 years after its discovery: a systematic review. Acta Trop 115: 5-13.

Daubener W, Remscheid C, Nockermann S, Pilz K, Seghruichini S, Bilzer T, Mackenzie C, Hadding U 1996. Anti-parasitic effector mechanisms in human brain tumor cells: role of interferon-gamma and tumor necrosis factor-alpha. Eur J Immunol 26: 487-498.

Dutra W, Gollob K 2008. Current concepts in immunoregulation and pathology of human Chagas disease. Curr Opin Infect Dis 21: 287-292.

Dvorak JA, Howe CL 1976. The attraction of Trypanosoma cruzi to vertebrate cells in vitro. $J$ Protozool 23: 534-537.

Epting CL, Coates BM, Engman DM 2010. Molecular mechanisms of host cell invasion by Trypanosoma cruzi. Exp Parasitol 126: 283-291.

Faria LO, Lima BD, de Sa CM 2008. Trypanosoma cruzi: effect of the infection on the $20 \mathrm{~S}$ proteasome in non-immune cells. Exp Parasitol 120: 261-268.

Fontana A, Fierz W, Wekerle H 1984. Astrocytes present myelin basic protein to encephalitogenic T-cell lines. Nature 307: 273-276.

Goldszmid RS, Sher A 2010. Processing and presentation of antigens derived from intracellular protozoan parasites. Curr Opin Iтmunol 22: 118-123.

Halonen SK, Lyman WD, Chiu FC 1996. Growth and development of Toxoplasma gondii in human neurons and astrocytes. $J$ Neuropathol Exp Neurol 55: 1150-1156.

Hamo L, Stohlman SA, Otto-Duessel M, Bergmann CC 2007. Distinct regulation of $\mathrm{MHC}$ molecule expression on astrocytes and microglia during viral encephalomyelitis. Glia 55: 1169-1177.

Hassan GS, Mukherjee S, Nagajyothi F, Weiss LM, Petkova SB, de Almeida SJ, Huang H, Desruisseaux MS, Bouzahzah B, Pestell RG, Albanese C, Christ GJ, Lisanti MP, Tanowitz HB 2006. Trypanosoma cruzi infection induces proliferation of vascular smooth muscle cells. Infect Immun 74: 152-159.

Hirayama M, Miyadai T, Yokochi T, Sato K, Kubota T, Iida M, Fujiki $\mathrm{N}$ 1988. Infection of human T-lymphotropic virus type I to astro- cytes in vitro with induction of the class II major histocompatibility complex. Neurosci Lett 92: 34-39.

Hirsch MR, Wietzerbin J, Pierres M, Goridis C 1983. Expression of Ia antigens by cultured astrocytes treated with gamma-interferon. Neurosci Lett 41: 199-204.

Lüder CG, Lang C, Giraldo-Velasquez M, Algner M, Gerdes J, Gross U 2003. Toxoplasma gondii inhibits MHC class II expression in neural antigen-presenting cells by down-regulating the class II transactivator CIITA. J Neuroimmunol 134: 12-24.

Mattosinho-Franca LC, Fleury RN, Ramos Jr HA, Lemos S, Melaragno Filho R, Pasternak J 1969. Moléstia de Chagas crônica associada a leucemia linfática: ocorrência de encefalite aguda como alteração do estado imunitário. Arq Neuropsiquiatr 27: 59-66.

Nagajyothi F, Weiss LM, Silver DL, Desruisseaux MS, Scherer PE, Herz J, Tanowitz HB 2011. Trypanosoma cruzi utilizes the host low density lipoprotein receptor in invasion. PLoS Negl Trop Dis 5: e953.

Oh JW, Schwiebert LM, Benveniste EN 1999. Cytokine regulation of $\mathrm{CC}$ and CXC chemokine expression by human astrocytes. J Neurovirol 5: 82-94.

OPS - Organización Panamericana de la Salud 2007. Reporte del grupo de trabajo científico sobre la enfermedad de Chagas. Available from: whqlibdocwhoint/hq/2007/TDR_SWG_09_spapdf.

Pires SF, da Rocha WD, Freitasm J, Oliveiram LA, Kitten GT, Machado CR, Penam SD, Chiari E, Macedo AM, Teixeira SM 2008. Cell culture and animal infection with distinct Trypanosoma cruzi strains expressing red and green fluorescent proteins. Int $J$ Parasitol 38: 289-297.

Pittella JEH 2009. Central nervous system involvement in Chagas disease: a hundred-year-old history. Trans $R$ Soc Trop Med Hyg 103: $973-978$

Rachid MA, Teixiera AL, Barcelos LS, Machado CRS, Chiari E, Tanowitz HB, Camargos ERS, Teixeira MM 2010. Role of endothelin receptors in the control of central nervous system parasitism in Trypanosoma cruzi infection in rats. J Neuroimmunol 220: $64-68$.

Roberts TK, Eugenin EA, Lopez L, Romero IA, Weksler BB, Couraud PO, Berman JW 2012. CCL2 disrupts the adherens junction: implications for neuroinflammation. Lab Invest 92: 1213-1233.

Roffe E, Silva AA, Marino AP, dos Santos P, Lannes-Vieira J 2003. Essential role of VLA-4/VCAM-1 pathway in the establishment of $\mathrm{CD}^{+}$T-cell-mediated Trypanosoma cruzi-elicited meningoencephalitis. J Neuroimmunol 142: 17-30.

Sartori MJ, Mezzano L, Lin S, Munoz S, de Fabro SP 2003. Role of placental alkaline phasphatase in the internalization of trypomastigotes of Trypanosoma cruzi into Hep2 Cells. Trop Med Int Health 8: 832-839.

Schenkman RPF, Vandekerckhove F, Schenkman S 1993. Mammalian cell sialic acid enhances invasion by Trypanosoma cruzi. Infect Immun 61: 898-902.

Seth P, Koul N 2008. Astrocyte, the star avatar: redefined. J Biosci 33: 405-421.

Silva AA, Roffe E, Marino AP, dos Santos PV, Quirico-Santos T, Paiva CN, Lannes-Vieira J 1999. Chagas disease encephalitis: intense $\mathrm{CD} 8^{+}$lymphocytic infiltrate is restricted to the acute phase, but is not related to the presence of Trypanosoma cruzi antigens. Clin Immunol 92: 56-66.

Sofroniew MV, Vinters HV 2010. Astrocytes: biology and pathology. Acta Neuropathol 119: 7-35. 
Soos JM, Morrow J, Ashley TA, Szente BE, Bikoff EK, Zamvil SS 1998. Astrocytes express elements of the class II endocytic pathway and process central nervous system autoantigen for presentation to encephalitogenic T cells. J Immunol 161: 5959-5966.

Tani M, Fuentes ME, Peterson JW, Trapp BD, Durham SK, Loy JK, Bravo R, Ransohoff RM, Lira SA 1996. Neutrophil infiltration, glial reaction and neurological disease in transgenic mice expressing the chemokine $\mathrm{N} 51 / \mathrm{KC}$ in oligodendrocytes. $J$ Clin Invest 98: 529-539.

Wang DD, Bordey A 2008. The astrocytes odyssey. Prog Neurobiol 86: 342-367.

Weinkauf C, Salvador R, Pereiraperrin M 2011. Neurotrophin receptor TrkC is an entry receptor for Trypanosoma cruzi in neural, glial and epithelial cells. Infect Immun 79: 4081-4087.
Williams DM, Remington JS 1977. Effect of human monocytes and macrophages on Trypanosoma cruzi. Immunology 32: 19-23.

Wilson EH, Hunter CA 2004. The role of astrocytes in the immunopathogenesis of toxoplasmic encephalitis. Int J Parasitol 34: $543-548$

Zhou J, Stohlman SA, Hinton DR, Marten NW 2003. Neutrophils promote mononuclear cell infiltration during viral-induced encephalitis. J Immunol 170: 3331-3336.

Zingales B, Andrade SG, Briones MRS, Campbell DA, Chiari E, Fernandes $\mathrm{O}$, Guhl F, Lages-Silva E, Macedo AM, Machado CR, Miles MA, Romanha AJ, Sturm NR, Tibayrenc M, Schijman AG 2009. A new consensus for Trypanosoma cruzi intraspecific nomenclature: second revision meeting recommends $\mathrm{TcI}$ to $\mathrm{TcVI}$. Mem Inst Oswaldo Cruz 104: 1051-1054. 